\title{
Lower Bounds of Concentration in a Small Open Economy
}

\author{
Pekka Ilmakunnas \\ Helsinki School of Economics and HECER
}

Discussion Paper No. 118

September 2006

ISSN 1795-0562

HECER - Helsinki Center of Economic Research, P.O. Box 17 (Arkadiankatu 7), FI-00014 University of Helsinki, FINLAND, Tel +358-9-191-28780, Fax +358-9-191-28781,

E-mail info-hecer@helsinki.fi, Internet www.hecer.fi 


\title{
Lower Bounds of Concentration in a Small Open Economy*
}

\begin{abstract}
We examine how Sutton's "bounds" approach works in a small country where industries have relatively high export and import intensities. Import competition is used as an indicator for the degree of competition in the low sunk cost industries. The bounds are estimated as stochastic frontiers, where observable industry characteristics, export intensity and entry barriers, are allowed to affect the mean and variance of the deviations from the frontier. In accordance with the theory, high R\&D intensity industries have a lower bound for concentration, which is higher than that for low sunk cost intensity industries. For high advertising industries the theory does not hold as well. High import competition leads to a higher bound in the low sunk cost industries.
\end{abstract}

JEL Classification: L11, L13, L60

Keywords: Concentration, sunk costs, R\&D, stochastic frontiers

Pekka Ilmakunnas

Department of Economics

Helsinki School of Economics

P.O. Box 1210

FI-00101 Helsinki

FINLAND

e-mail: pekka.ilmakunnas@hse.fi

* Early versions of this paper have been presented at the EARIE conference in Dublin, Annual Symposium of Finnish Economists in Turku, and seminars at the Finnish Competition Authority and the National Technology Agency (Tekes). I am thankful to the seminar participants, especially John Sutton, for useful discussions, and to Satu Nurmi from Statistics Finland for constructing the data set used in this study. Academy of Finland has supported the research (project 49153). 


\section{Introduction}

During the heyday of the structure-conduct-performance (SCP) paradigm there was much research on the measurement of concentration and development of concentration measures. Concentration was also analyzed in the open economy context by adjusting concentration ratios for exports and imports or by explaining domestic concentration by export and import intensity. The analysis of market structure has gained new interest since the 1990s. One major factor behind this has been the research of Sutton (1991, 1998, 2006). He has developed theories on what determines a lower bound for concentration. The emphasis in empirical work is then not in explaining the actual level of concentration in different industries, but rather on testing whether different kinds of industries have different lower bounds for their concentration levels. The emphasis is on how endogenous sunk costs in the form of advertising or R\&D lead to a lower bound for concentration that is higher than the bound in industries without such sunk costs. With a few exceptions (Lyons and Matraves, 1996, Lyons, Matraves, and Moffatt, 2001) the bounds approach has not been discussed in an open economy context.

This paper has two purposes. First of all, we want to examine how well the predictions of the "bounds" theory hold in a small open economy. It is not immediately clear that they should hold, since many relevant markets are not national, but rather international. Further, in a small country most industries have a fairly small number of firms and high concentration. However, if the results are consistent with the bounds theory, they actually give strong support for it as it since predicts well even in these "unfavorable" conditions. In particular, we take into account the open economy aspect by defining the degree of competition in industries based on the role of imports. Our second goal is to examine whether industries deviate from the lower bound in such a systematic manner that can be explained by variables that describe for example the entry conditions of the industries. This is done by estimating the bound as a stochastic frontier, where various variables, including export intensity and measures of entry barriers, affect the mean and variance of a truncated error term. Hence deviations from the bound are treated like "inefficiencies" in frontier-based cost efficiency analysis. In a way our approach merges the bounds 
approach and the older approach where concentration was directly explained by different characteristics of the industries. The data that we use is from Finnish manufacturing.

Our results support the "bounds" approach as far as R\&D is concerned, but for advertising the results are less conclusive. It also appears that import intensity can be regarded as a measure of the degree of competition in low sunk cost industries. The results are relatively robust to different definitions of $R \& D$ intensity and to alternative measures of concentration. We also find that systematic deviations from the lower bound can be explained by observable industry characteristics.

The structure of the paper is as follows. In section 2 we briefly review earlier empirical research on Sutton's endogenous sunk costs model. In section 3 we present the data and econometric approach to be used and in section 4 we report the estimation results. Section 5 concludes the paper.

\section{Previous research on the endogenous sunk costs model}

Although theory does not give straightforward guidelines on the relationship between the number of firms and degree of competition, some limits to their connection can be stated (Sutton, 1991, 2002). The number of firms affects the level of the price negatively in all market structures, except for the extreme cases of perfect collusion and homogeneous goods Bertrand competition. On the other hand, given the market size, the more firms there are, the smaller is the scale of production and the higher the price has to be for the firms to survive. If the market size grows, it can accommodate more firms. These relationships determine an inverse relationship between market size and the inverse of the maximum possible number of firms, i.e. the lower bound for concentration. If all $\mathrm{N}$ firms in an industry were of equal size, market structure could be measured with the number of firms. The lower bound is an inverse relationship between market size and $1 / \mathrm{N}$, which in this equal firm size case equals the Herfindahl index H. If firm sizes vary, the bound, now an inverse relationship between a concentration measure and market size is at some higher level. As emphasized by Sutton (1991), the actual location of industries in the 
concentration-market size space depends on the history of the industries, random events, etc.

An essential feature of the bounds approach is the incorporation of endogenous sunk costs in the determination of market structure. These include advertising and research and development expenses. On one hand, they increase the customers' willingness to pay for the product, but on the other hand, they increase costs and raise the price required for firm survival. As a result, the first prediction of the theory is that the lower bound of concentration has to be at a higher level and industries with this kind of sunk costs tend to be more concentrated. The second prediction is that when market size grows, the firms may invest even more in sunk costs and concentration may decrease only slowly, and the lower bound is less steep than in low sunk cost industries. In the industries with no sunk costs increasing degree of price competition shifts the bound up (given market size), since the number of firms has to fall for the firms to survive. This is the third prediction of the theory.

In practice, the bound is estimated by regressing a measure of concentration on market size. The concentration measure most typically used is logit transformation of a concentration ratio, $\ln (C /(1-C))$, but also logit transformation of Herfindahl index has been used (Lyons and Matraves, 1996), or an untransformed concentration ratio. The explanatory variable is usually some measure of market size relative to setup costs, $S / \sigma$. To obtain a suitable convex form for the bound, this variable often enters in the form $1 / \ln (S / \sigma)$.

The definition of sunk cost industries varies somewhat in the literature. The empirical work in Sutton (1991) considered only advertising, but the approach has been applied by subsequent writers to both advertising and R\&D (Robinson and Chiang, 1996, Lyons and Matraves, 1996, Symeonidis, 2000, Lyons, Matraves, and Moffatt, 2001, Giorgetti, 2003). ${ }^{1}$ Industries can be divided to two types: 1: industries with no endogenous sunk

\footnotetext{
1 Sutton (1998) derives a lower bound relationship between concentration and market segmentation, measured by the number of submarkets in the industry. This relationship should be different in high R\&D
} 
costs, and 2: endogenous sunk cost industries. Group 2 can be further divided to 2A: advertising intensive industries, 2R: R\&D intensive industries, and 2AR: both advertising and R\&D intensive industries. Given the market size, the lower bound for concentration should be lowest in group 1; in group 2 it is higher and does not necessarily decrease monotonically with market size. Various authors have used slightly different combinations of these industry groups. Type 1 industries can further be divided to high and low competition industries. We will use import intensity variables to measure the degree of competition in these industries.

To test the hypothesis, one can pool all industries in estimation and include separate intercepts for each industry type. Lyons and Matraves (1996) include the level of integration in the equation for the bound, estimated using EU-level concentration and market size data. This is based on the argument that the degree of integration of markets should theoretically have an influence on the level of the bounds; this influence can be different in the different types of industries. Lyons, Matraves, and Moffatt (2001) use a switching regression model to determine whether the appropriate market is national or EU market. Symeonidis (2000) includes a dummy variable describing the competition regime, influenced by changes in cartel policy. Robinson and Chiang (1996) use separate estimations for industries with different types of competition. Sometimes also the slope coefficients are allowed to vary by industry type to test the second prediction.

Sutton (1991) estimated the model using a method that imposed the constraint that all observations are above the boundary. Since the model includes two parameters, constant and the coefficient of $1 / \ln (S / \sigma)$, the boundary goes through two observation points. This method was used also by Robinson and Chiang (1996) and Marin and Siotis (2002), and Giorgetti (2003) compares this method and quantile regression. A stochastic frontier has been estimated by Lyons and Matraves (1996), and Marin and Siotis (2002). The stochastic frontier approach allows industries to be in disequilibrium, i.e. it is possible that they are occasionally situated below the theoretical (equilibrium) lower bound. An

intensity and low R\&D intensity industries. See also Marin and Siotis (2002). Unfortunately, we have no suitable measures for the number of submarkets in our data. 
average frontier (i.e., OLS estimation) has been used by Symeonides (2000), who found that the errors had a wrong skew to be based on a stochastic frontier, and by Lyons, Matraves, and Moffatt (2001), among others.

The traditional SCP way of examining the determinants of concentration was to include several variables together in a regression model for concentration (see e.g. Davies, 1989). These variables typically included advertising intensity and/or R\&D intensity, measures of barriers to entry, and often also export and import shares. In the bounds approach the model is estimated separately for different types of industries without including R\&D or advertising as explanatory variables. One purpose of this paper is to examine whether some of the "traditional" variables could still be used for explaining how far different industries are from the lower bound. If there are factors that influence the competitive situation, entry etc. in the markets, they could be potential determinants of the position of the industries in the concentration - market size space. Note that this is different from saying that in the low sunk cost industries high and low competition industries should have different limiting levels of concentration. Below we define the high/low competition distinction of the low sunk cost industries and the corresponding bounds on the basis of imports. The industries may, however, differ systematically from these bounds if they have differences in the ease of domestic entry, for example. Technically, we estimate the model as a stochastic frontier, where the explanatory factors are included in the mean and variance of a truncated error term. These explanatory variables include export intensity and alternative measures of entry barriers.

\section{The data and econometric approach}

We use data from 78 Finnish 4-digit manufacturing industries from 1975-94. ${ }^{2}$ The data are based on information on plants in the Industrial Statistics. There is a lower size limit of 5 employees before a plant is included. The plants are aggregated to firms to analyze concentration. However, because of the lower size limit, the concentration figures will

\footnotetext{
${ }^{2}$ See Wahlroos and Bäckström (1980) for an analysis of concentration in Finnish industries in the SCP tradition.
} 
slightly overstate actual concentration. After 1994 there is a break in the statistics, since after that year only plants belonging to firms with at least 20 employees are included. Therefore we end the data period in 1994. All variables are measured as averages over 5year periods, 1975-79, 1980-84, 1985-89, and 1990-94. This averaging accounts for possible random measurement errors in variables and also lessens problems caused by the fact that in many variables there is fairly little year-to-year variation. We therefore have a (pseudo) panel of 78 cross-section observations over 4 periods, with a total of 312 observations.

As to the measure of concentration, we use the concentration ratio. Since in a small country like Finland there are industries with very few producers, 4- or 5-firm concentration ratios may be equal to 1 in many cases. This is why we have used $C 3,3$ firm concentration ratio, although even here some values are equal to 1 . As an alternative measure, we also use the Herfindahl index. The basic data are based on plants but include firm codes so that the plants can be aggregated to firms within each industry. The concentration ratios are based on these data on firms. Concentration can be measured with value added or gross production. We have opted for measuring the concentration of gross production, since this is closest to sales concentration, the measure most frequently used, and because with value added we would have the problem of some negative observations.

The basic equation, introduced by Sutton (1991), is

$\ln (C 3 /(1-C 3))=\alpha+\beta[1 / \ln (S / \sigma)]+\varepsilon$

The dependent variable is a logit transformation of the concentration ratio. Since in some industries the three-firm concentration ratio is equal to 1 , the transformation was calculated as $\ln ((C 3+c) /(1-C 3+c))$ where $c$ is a small constant (e.g. Amemiya, 1985). We 
chose $c=0.001$, which implies that the logit transformation equals 6.90875 when $C 3=$ $1 .{ }^{3}$

The explanatory variable is $1 / \ln (S / \sigma)$, where $S$ is industry output and $\sigma$ is setup cost. The ratio $\sigma / S$ is measured by $M E S * K / S$, the value of the industry capital-output ratio $K / S$, multiplied by minimum efficient scale $M E S$. Capital stock $K$ is the value of machinery and buildings in the industry and $M E S$ is measured by the average size of the plants producing more than the median plant, relative to industry output. ${ }^{4}$ The idea is that an entering firm needs a fraction $M E S$ of the capital stock $K$. Both $M E S$ and the industry size $\mathrm{S}$ are measured in terms of gross production.

To allow for disequilibrium deviations from the lower bound, we estimate the model as a stochastic frontier. The error term of the equation is assumed to have the form $\varepsilon=v+u$, where $\mathrm{v}$ is normally distributed, $N\left(0, \sigma_{v}^{2}\right)$, and $u$ obtains only positive values. Since the bound is a lower bound for concentration, the relationship is analogous to a cost frontier; hence the positive sign of $u$. The $u$ term is "inefficiency" or here deviation from the bound. We assume that the error component $u$ is distributed as $N\left(\mu, \sigma_{w}^{2}\right)$ truncated at zero. Further, the mean $\mu$ and variance $\sigma_{u}^{2}$ are allowed to depend on various variables Z: $\mu=$ $Z \gamma$ and $\sigma_{u}^{2}=\exp (Z \phi)$. This formulation allows a variable to influence deviation from the bound by shifting the truncation point and/or by shifting the variance of the inefficiency term. An increase in the mean would shift the distribution of deviations from the bound upwards. An increase in the variance would stretch the distribution, making larger deviations more likely. Including the variables in both terms also allows for nonmonotonic effects (Wang, 2002). ${ }^{5}$ The variance of the symmetric error $v$ is assumed constant, parameterized as $\sigma_{v}^{2}=\exp (\theta)$.

\footnotetext{
${ }^{3}$ The constant cannot be very small, since otherwise when $C 3=1$, the logit transformation would give very large values. In this case $\ln ((1+c) / c)=\ln (1+(1 / c)) \approx 1 / c \rightarrow \infty$ when $c \rightarrow 0$. As outliers these large values might have an impact on the estimated bound.

${ }^{4}$ There are, of course, problems with this measure of MES, as with all other suggested proxies, since they tend to be related to concentration (see Davies, 1989). In Sutton (1991) MES is measured by output of median plant. Other authors have used other market size measures, for example $S / M E S$ instead of $S / \sigma$, and other measures for $M E S$, e.g. engineering estimates.

5 See also Kumbhakar and Lovell (2000) for a discussion on different ways of parameterizing the inefficiency terms.
} 
The industries are divided to groups on the basis of their R\&D expenditure/sales and marketing expenditure/sales ratios. Information on these expenditures was available from Income Statements Statistics and R\&D Statistics. Average values of the ratios are calculated for each industry. Those industries are classified as R\&D (advertising) intensive, which have $\mathrm{R} \& \mathrm{D} / \mathrm{sales}$ (marketing expenses/sales) ratio above the overall average. The high sunk cost industries (group 2) is the union of these industry groups. We end up with 20 R\&D intensive (group 2R) and 26 advertising intensive (group 2A) industries (see Table 1). There are only 5 industries where both R\&D and advertising were high (group 2AR). Because of the small number of industries in this group, it is not treated separately. The $2 \mathrm{R}$ and $2 \mathrm{~A}$ groups are allowed to have separate intercepts and slopes in the model.

\section{TABLE 1 HERE}

In other studies, the classifications have often been based on advertising/sales or $\mathrm{R} \& \mathrm{D} / \mathrm{sales}$ ratios of $1 \%$. The cutoff point for our $\mathrm{R} \& \mathrm{D} /$ output ratio is $0.4 \%$ and for the marketing expenses/output ratio it is $2.6 \%$. Therefore, our criterion for R\&D intensity may be more lax and for advertising intensity more conservative than in other studies. However, there are likely to be measurement problems with these variables, since the industry data on $R \& D$ and marketing expenses are based on a sample of firms, whereas the industry gross output figures are based on all plants (except for the smallest). Therefore, the ratios are not directly comparable to those used in other studies. Our approach of comparing the industry ratios to the overall average ratio minimizes possible problems from using a pre-assigned cut-off point in the presence of measurement errors.

We define the group of low sunk cost industries (group 1) as the intersection of the low R\&D and low advertising groups. This includes 37 industries. Since the intensity of competition may influence the lower bound in the low $R \& D$ and low advertising industries, we separate this group further to import intensive and import non-intensive industries. These are denoted type 1I and type 1NI, respectively. Data on imports are 
available only from the year 1985 onwards. We calculate imports/gross output ratios for the industries and average these over time. Those industries are defined as import intensive that have average imports/gross production ratio above the overall average. We end up with 11 type 1I industries, i.e. low sunk costs industries that are import intensive (see Table 1). These are allowed to have a separate intercept and slope. Similar analysis could be made by classifying the industries to export intensive and export non-intensive. However, since competition abroad need not affect the behavior of the firms in the home markets, the effect on concentration is unclear, so we do not differentiate the industries by exports.

The equation to be estimated is an extension of (1) with both the constant term and the slope of the equation allowed to vary by industry group:

$\ln (C 3 /(1-C 3))=\alpha+\alpha_{R} R D+\alpha_{A} A D V+\alpha_{I} I M P *(1-R D) *(1-A D V)+\beta[1 / \ln (S / \sigma)]+$ $\beta_{R}[1 / \ln (S / \sigma)] * R D+\beta_{A}[1 / \ln (S / \sigma)] * A D V+\beta_{I}[1 / \ln (S / \sigma)] * I M P *(1-R D) *(1-A D V)+\varepsilon$

where $R D, A D V$, and $I M P$ are dummy variables for high $\mathrm{R} \& \mathrm{D}$ industries, high advertising intensity industries, and high import competition industries, respectively. The constant for the low sunk cost industries (both low R\&D and low advertising) with low import competition (group 1NI) is $\alpha$, for the low sunk cost industries with high import competition (group 1I) $\alpha+\alpha_{I}$, for high R\&D industries (group 2R) $\alpha+\alpha_{R}$, and for high advertising industries (group 2A) it is $\alpha+\alpha_{A}$. The slopes of the bound can be calculated for each group in a similar way. The data set is a panel, but since we are interested in finding a bound that envelops all industries, it does not make sense to include industry fixed effects. In effect, all industries within a group should have the same intercept.

To check the robustness of the results, we also estimate the model so that the high and low $R \& D$ industries are determined by quartiles of the $R \& D /$ sales-ratio. The high $R \& D$ industries are in this case defined to be those in the highest quartile of the distribution. A similar group is used for high advertising industries. We define as low sunk cost industries such cases where both R\&D intensity and advertising intensity are below the 
median, i.e. in the two lowest quartiles. High sunk cost industries are such that either $\mathrm{R} \& \mathrm{D}$ or advertising or both are in the top quartile. In these estimations the quartiles where either R\&D or advertising is in the third quartile and the other one in the bottom three quartiles are left out. With this classification we have 36 high sunk cost industries, 18 low sunk cost industries, and 24 "middle" industries (see Table 2). Out of the sunk cost industries, 19 have high R\&D and 20 high advertising, so that only 3 industries have both high $\mathrm{R} \& \mathrm{D}$ and high advertising intensity. The number of high $\mathrm{R} \& \mathrm{D}$ industries is almost the same as in Table 1 where above average R\&D intensity was used as the cutoff point. This can be explained by the strongly skewed distribution of the R\&D/output ratio. Among the 18 low sunk cost industries 6 have high import competition.

\section{TABLE 2 HERE}

How do other variables influence the level of concentration? They could be included into the model in various ways. However, beyond the variables (setup costs and various dummies and their interactions) that by theory should affect the bound, inclusion of other variables directly as explanatory variables may not be justified. Instead, one could argue that many of the other variables that potentially affect concentration should not influence the lower bound, but rather determine how far different industries are from the bound. While the bounds approach states that theory only gives the lower bound for concentration, it is nevertheless interesting to see how deviations from the bound can be explained by variables that have traditionally been used as determinants of concentration. Our approach is to include this kind of variables in the mean $\mu$ and variance $\sigma_{u}^{2}$ of the truncated error component $u$.

We use the following variables in the mean and variance terms. Cost disadvantage ratio (gross output per worker in plants producing less than the median plant, divided by the corresponding figure for plants producing more than the median plant) takes into account the costs that are caused by entry at suboptimal scale. Its impact on concentration should be positive, since high cost disadvantage raises entry barriers. The variable also accounts for the fact that the setup cost variable that is used for estimating the lower bound need 
not measure the setup costs of those firms operating below the MES level (cf. Sutton, 1991, p. 95).

If the industry has many multi-plant firms, there may be economies in operating several plants as opposed to operating in several single-plant firms. This may create a disadvantage for entering firms that cannot start with several plants (Duetsch, 1984). Multiplant economies are difficult to measure, so we use the variable share of multiplant firms in the industry as a proxy measure of the importance of multiplant activity. It is expected to have a positive impact on the deviation of actual concentration from the lower bound.

We also include industry export intensity (share of production that goes to exports) as an explanatory variable ${ }^{6}$. We argued above that it may be best not to include exports in the equation that defines the lower bound. The impact of exports in the mean and variance of $u$ is not clear a priori either. On one hand, intense competition in export markets can have effects similar to those of imports, i.e. higher concentration in the low R\&D and low advertising industries. On the other hand, it is possible that export markets make it possible for more firms to survive in a country that has small domestic markets. This would lead to lower domestic concentration.

\section{Estimation results}

Table 3 presents the maximum likelihood estimation results for the model. Model 1 refers to definition of R\&D and advertising intensive industries based on the means of $\mathrm{R} \& \mathrm{D} / \mathrm{sales}$ and advertising/sales ratios, whereas Model 2 refers to definitions based on the quartiles of the distributions of the ratios. The first two columns show the results when $C 3$ is the concentration measure and the last two columns for the Herfindahl index.

\footnotetext{
${ }^{6}$ The export share data are from Industrial Statistics and available for all the years, in contrast to the imports data which are from Foreign Trade Statistics.
} 
The estimated coefficient for high R\&D dummy is positive and hence the hypothesis about a higher lower bound for the R\&D intensive industries gets support. The comparison of import intensive and non-intensive industries with low sunk costs shows that those industries that face tougher import competition have a higher lower bound, as predicted. When $S / \sigma$ approaches infinity, the constant term $\alpha$ in the model (Model 1) gives the limiting lower bound for $\ln (C 3 /(1-C 3)$ in the low sunk cost, low import competition industries. Hence, the limiting lower bound for $C 3$ is $e^{\alpha} /\left(1+e^{\alpha}\right)$. The limiting bounds for the other industry groups are calculated in a similar manner. These limiting concentration levels are shown in Table 4. Using the estimates of Model 1 in Table 3 the implied limiting concentration ratio $C 3$ is 0.226 for the high $\mathrm{R} \& \mathrm{D}$ intensity industries, 0.075 for the low sunk costs, low import competition industries and 0.196 for the low sunk costs, high imports industries. As for advertising, the evidence is mixed. The dummy for advertising intensive industries has a positive and significant coefficient, but it is so low that the implied limiting concentration level is 0.117 . This is above the limiting concentration of the low sunk costs, low import competition industries, but below that of the high import competition industries.

\section{TABLES 3 AND 4 HERE}

According to the theory, the bound should be less steep in the sunk cost industries. This is, however, not quite supported by the results. The estimate for the slope coefficient is highest (i.e., the slope steepest) for the reference group, low sunk costs, low import competition industries. Advertising intensive industries have the second highest and R\&D intensive industries the third highest slope coefficient. The slope is the least steep in the low sunk cost, high competition group. Figure 1 shows the deterministic parts of the stochastic bounds.

\section{FIGURE 1 HERE}

We also report in Table 3 the coefficients of the variables in the mean and variance equations. The total effect of a variable on the mean $E(u)$ of the truncated error depends 
on the effect of the variable on both $\mu$ and $\sigma_{u}^{2}$. Correspondingly, the total effect on $\operatorname{Var}(u)$ depends on both terms (see Wang, 2002). ${ }^{7}$ These marginal effects, calculated for each data point and averaged over the sample, are shown in Table 5. The share of multi-plant firms has a highly significant positive effect both in the mean and variance equation. Also the marginal effects on the mean and variance are positive. This is consistent with multiplant economies. Since all the explanatory variables are shares, the magnitudes of the marginal effects are such that, a one percentage point increase in a variable has a marginal effect equal to an entry in Table 5 multiplied by 0.01 . Hence, a one percentage point increase in the share of multiplant firms would increase the mean $E(u)$ by 0.05 and the variance $\operatorname{Var}(u)$ by 0.22 . Cost disadvantage has a negative sign in the mean equation, but a positive one in the variance equation. The marginal impact on the mean is negative, but but small, and the impact on the variance is positive (Table 5). Entry at suboptimal scale may be costly, which contributes to high concentration in stretching the distribution of deviations from the bound (although at the same time the distribution shifts slightly closer to the bound). Finally, export share has a positive impact in the mean equation, but a negative one in the variance equation. Its marginal impact on both the mean and variance of the truncated error is negative. It seems that export activity makes it possible for more firms to exist in a small market.

\section{TABLE 5 HERE}

To check the robustness of the results we defined the high and low sunk cost industries on the basis of the quartiles of $\mathrm{R} \& \mathrm{D}$ and advertising intensity. The results on the stochastic frontier are shown in column 2 of Table 3 and the limiting levels of concentration in column 2 of Table 4. The constant for the low sunk costs, low import competition group implies a limiting level of concentration 0.075 when market size grows to infinity. The import competition dummy has non-significant coefficient. The implied limiting level of concentration is 0.098 . The limiting level of concentration for

\footnotetext{
${ }^{7}$ In production models $E(u)$ measures inefficiency and $\operatorname{Var}(u)$ can be interpreted as a measure of production uncertainty. There is no counterpart for these interpretations in our case. The terms measure different ways in which industries can deviate from the theoretical bound.
} 
the high R\&D intensity group is 0.176 , and for the high advertising group 0.142 . Except for the high advertising group, these values are somewhat lower than in Model 1. The results support the hypothesis that high sunk cost industries have higher limiting levels of concentration. The slopes of the bounds for the high sunk cost industries are less steep than for the other industries, as expected. As to the explanatory variables in the mean and variance equations, the signs of the variables are the same as before, but the coefficient of export share is not significant. The average marginal impacts on the mean and variance are fairly similar to those in Model 1.

Finally, we carried out the estimations with the Herfindahl index as the measure of concentration. The estimates using the two different definitions of R\&D and advertising intensity are shown in the last two columns of Table 3 and the limiting levels of the $\mathrm{H}$ index in the last two columns of Table 4. The estimates agree with those obtained with C3: The low sunk cost, low import competition industries have the lowest limiting $H$ value and the steepest slope for the bound. The high R\&D industries have the highest limiting value for $H$ and the least steep slope for the bound. The ranking of the low sunk cost, high import competition and high advertising industries depends on the way the high sunk cost industries have been defined. The main difference to the estimates with $C 3$ in the impact of the other explanatory variables is that now cost disadvantage has a negative marginal effect also on $\operatorname{Var}(u)$, although the magnitude of the effect is small. With the alternative definition of sunk cost industries (Model 2), export share now has a positive, but very small average marginal effect on $\operatorname{Var}(u)$.

All in all, the evidence gives mixed support for the endogenous sunk cost model. With respect to R\&D the results support the "bounds" approach, although the differences between the limiting concentration ratios of high and low sunk cost industries are not big. In case of advertising, the results are more inconclusive. One reason for this may be that in an open economy sunk costs created by advertising by domestic firms is not that important from the point of view of the market structure, if at the same time there is advertising by foreign producers. Thus the main difference between industries seems to arise from import competition rather than advertising. It is likely that in consumer goods 
industries the relevant markets are e.g. EU-wide (as in Lyons and Matraves, 1996), and in small countries the theory does not fit well.

\section{Conclusions}

We have tested Sutton's theory of concentration with Finnish data, using stochastic frontiers to estimate lower bounds for concentration. It seems that in a small open economy there are some features that need to be taken into account. First, in a small country industries tend to be highly concentrated, which leads to difficulties in the use of even 3-firm concentration ratios. We have adjusted the logit transformations of such concentration ratios, although the adjustment is not unproblematic. The Herfindahl index does not suffer from these problems and gives results that are consistent with those obtained using the $C 3$ concentration ratio. Another issue is how to treat foreign competition. Rather than adjusting the concentration ratios for foreign trade, we have treated import intensity as an indicator of competition. Consequently, we have allowed for separate parameters for import intensive and non-intensive industries to test whether the degree of competition affects the lower bound of concentration.

The results on $R \& D$ intensive and non-intensive industries seem consistent with the predictions of the theory, although the differences between industries are not big. The lower bound for the R\&D intensive industries is at a higher level than that of low sunk cost industries. On the other hand, among the low sunk cost industries, those facing tough import competition have a higher limiting level of concentration than industries with less foreign competition. As to advertising, the lower bound of concentration in advertising intensive industries is at a lower level than in the industries with low sunk costs and high import competition, which is in conflict with the theory. This result does, however, change if we use another definition for the low sunk cost and high sunk cost industries. In any case, it seems that in a small open economy the exposure to foreign competition is a more decisive factor than advertising-related sunk costs. We have also tested whether deviations of $C 3$ from the lower bounds can be explained by observable industry characteristics. The share of multiplant firms had a positive effect both on the mean and 
variance of deviations from the bound. This can be interpreted to be an effect of multiplant economies. Export intensity had a negative impact on both. The results indicate that export activity tends to allow more firms to exist, thereby lowering concentration. Cost disadvantage of suboptimal scale plants had a positive effect on variance, but a negative one on the mean of deviations from the lower bound. The impact of scale-related entry barriers is therefore mixed.

\section{References}

Amemiya, T., Advanced Econometrics, Harvard University Press, 1985

Davies, S., "Concentration", in S. Davies et al., Economics of Industrial Organisation, Longman, 1989, 73-126

Duetsch, L.L., "Entry and the extent of multiplant operations", Journal of Industrial Economics 32, 1984, 477-487

Giorgetti, M. L., Lower bound estimation - quantile regression and simplex method: An application to Italian manufacturing sectors", Journal of Industrial Economics 51, 2003, $113-120$

Kumbhakar, S.C. and Lovell, C.A.K., Stochastic Frontier Analysis, Cambridge University Press, 2000

Lyons, B. and Matraves, C., "Industrial concentration", in S. Davies, B. Lyons et al., Industrial Organization in the European Union: Structure, Strategy, and the Competitive Mechanism, Oxford University Press, 1996, 86-104

Lyons, B., Matraves, C., and Moffatt, P., "Industrial concentration and market integration in the European Union", Economica 68, 2001, 1-26

Marin, P. L. and Siotis, G., "Innovation and market structure: An empirical evaluation of the 'bounds approach' in the chemical industry", CEPR Discussion Paper No. 3162, 2002 Robinson, W.T. and Chiang, J., ”Are Sutton's predictions robust?: Empirical insights into advertising, R\&D, and concentration", Journal of Industrial Economics 44, 1996, 389408 
Sutton, J., Sunk Costs and Market Structure - Price Competition, Advertising and the Evolution of Concentration, MIT Press, 1991

Sutton, J., Technology and Market Structure - Theory and History, MIT Press, 1998

Sutton, J., "Market structure: The bounds approach", in M. Armstrong and R. Porter, eds., Handbook of Industrial Organization, vol. 3, Elsevier, 2006 (forthcoming)

Symeonidis, G., "Price competition and market structure: The impact of cartel policy on concentration in the UK", Journal of Industrial Economics 48, 2000, 1-26

Wahlroos, B. and Backström, M., "R\&D intensity with endogenous concentration:

Evidence for Finland", Empirical Economics 7, 1982, 13-22

Wang, H.-J., "Heteroscedasticity and non-monotonic efficiency effects of a stochastic

frontier model", Journal of Productivity Analysis 18, 2002, 241-253 


\begin{tabular}{ll|cc|l}
\hline & & \multicolumn{2}{|c|}{ R \& D intensity } & \\
& & Below average & Above average & Total \\
\hline Advertising & Below average & $37(11)$ & 15 & 52 \\
intensity & Above average & 21 & 5 & 26 \\
\hline & Total & 58 & 20 & 78 \\
\hline
\end{tabular}

Note: The industries in the shaded area are defined as high sunk cost industries and those in the unshaded area as low sunk cost industries. The number of high imports, low sunk cost industries is in parentheses.

Table 1. The number of industries in different groups, based on average values of R\&D and advertising intensity (Model 1)

\begin{tabular}{|c|c|c|c|c|c|c|}
\hline & \multicolumn{4}{|c|}{$R \& D$ intensity quartiles } & \multirow[b]{2}{*}{ Total } \\
\hline & & 1 & 2 & 3 & 4 & \\
\hline \multirow{5}{*}{$\begin{array}{l}\text { Advertising } \\
\text { intensity } \\
\text { quartiles }\end{array}$} & 1 & $6(2)$ & $5(0)$ & 5 & 4 & 20 \\
\hline & 2 & $2(1)$ & $5(3)$ & 6 & 6 & 19 \\
\hline & 3 & 3 & 4 & 6 & 6 & 19 \\
\hline & 4 & 9 & 5 & 3 & 3 & 20 \\
\hline & Total & 20 & 19 & 20 & 19 & 78 \\
\hline
\end{tabular}

Note: The industries in the darker shaded area are defined as high sunk cost industries and those in the lighter shaded area as low sunk cost industries. The industries in the unshaded are were not used in the analysis. The number of high imports, low sunk cost industries is in parentheses.

Table 2. The number of industries in different groups, based on quartiles of R\&D and advertising intensity (Model 2) 


\begin{tabular}{|c|c|c|c|c|}
\hline & \multicolumn{2}{|c|}{$\ln (C 3 /(1-C 3))$} & \multicolumn{2}{|c|}{$\ln (H /(1-H))$} \\
\hline & Model 1 & Model 2 & Model 1 & Model 2 \\
\hline Parameters of the bound & & & & \\
\hline Constant & $\begin{array}{l}-2.518 * * * \\
(0.132)\end{array}$ & $\begin{array}{l}-2.566^{* * *} \\
(0.282)\end{array}$ & $\begin{array}{l}-4.539 * * * \\
(0.137)\end{array}$ & $\begin{array}{l}-4.475^{* * *} \\
(0.242)\end{array}$ \\
\hline$R D$ & $1.284 * * *$ & $1.024 * * *$ & $1.479 * * *$ & $1.194 * * *$ \\
\hline & $(0.149)$ & $(0.202)$ & $(0.147)$ & $(0.223)$ \\
\hline$A D V$ & $0.497 * * *$ & $0.766^{*}$ & $0.759 * * *$ & $0.823 * * *$ \\
\hline & $(0.179)$ & $(0.418)$ & $(0.171)$ & $(0.250)$ \\
\hline$I M P^{*}(1-R D) *(1-A D V)$ & $1.106 * * *$ & 0.351 & $0.857 * * *$ & 0.687 \\
\hline & $(0.195)$ & $(0.689)$ & $(0.204)$ & $(0.534)$ \\
\hline $1 / \ln (S / \sigma)$ & $6.830 * * *$ & $6.890 * * *$ & $6.620 * * *$ & $6.091 * * *$ \\
\hline & $(0.461)$ & $(1.189)$ & $(0.436)$ & $(0.612)$ \\
\hline$R D *(1 / \ln (S / \sigma))$ & $-3.170 * * *$ & $-2.288 * * *$ & $-3.352 * * *$ & $-2.616 * * *$ \\
\hline & $(0.455)$ & $(0.576)$ & $(0.412)$ & $(0.449)$ \\
\hline$A D V^{*}(1 / \ln (S / \sigma))$ & $-1.255 * *$ & -2.212 & $-2.144 * * *$ & $-2.379 * * *$ \\
\hline & $(0.586)$ & (1.411) & $(0.531)$ & $(0.589)$ \\
\hline $\operatorname{IMP} *(1-R D) *(1-A D V) *(1 / \ln (S / \sigma))$ & $-3.709 * * *$ & -1.748 & $-2.096 * * *$ & $-2.030 * *$ \\
\hline & $(0.490)$ & (1.293) & $(0.528)$ & $(0.851)$ \\
\hline Parameters of the mean of the truncated error & & & & \\
\hline Constant & 0.215 & 0.408 & -0.787 & $5.889 *$ \\
\hline Cost disadvantage & $\begin{array}{l}-15.365^{* * * *} \\
(3.954)\end{array}$ & $\begin{array}{l}-8.998 * \\
(3.777)\end{array}$ & $\begin{array}{l}-22.731^{* * * *} \\
(7.658)\end{array}$ & $\begin{array}{l}-14.744^{*} \\
(8.749)\end{array}$ \\
\hline Share of multiplant firms & $\begin{array}{l}7.865^{* *} \\
(4.049)\end{array}$ & $\begin{array}{l}10.760^{*} \\
(5.853)\end{array}$ & $\begin{array}{l}5.586 \\
(6.240)\end{array}$ & $\begin{array}{l}8.769^{*} \\
(5.169)\end{array}$ \\
\hline Export share & $\begin{array}{l}7.717 * * * \\
(2.775)\end{array}$ & $\begin{array}{l}4.627^{*} \\
(2.573)\end{array}$ & $\begin{array}{l}11.047 * * \\
(4.669)\end{array}$ & $\begin{array}{l}-1.555 \\
(4.552)\end{array}$ \\
\hline Period dummies & Yes & Yes & Yes & Yes \\
\hline Parameters of the variance of the truncated error & & & & \\
\hline Constant & $\begin{array}{l}0.666 \\
(0.570)\end{array}$ & $\begin{array}{l}0.330 \\
(0.879)\end{array}$ & $\begin{array}{l}1.426^{* *} \\
(0.573)\end{array}$ & $\begin{array}{l}-0.507 \\
(1.422)\end{array}$ \\
\hline Cost disadvantage & $\begin{array}{l}2.078 * * * \\
(0.378)\end{array}$ & $\begin{array}{l}1.710 * * * \\
(0.494)\end{array}$ & $\begin{array}{l}1.325 * * * \\
(0.357)\end{array}$ & $\begin{array}{l}1.792 * * * \\
(0.600)\end{array}$ \\
\hline Share of multiplant firms & $\begin{array}{l}4.473 * * * \\
(0.822)\end{array}$ & $\begin{array}{l}4.784 * * * \\
(1.455)\end{array}$ & $\begin{array}{l}3.627 * * * \\
(0.783)\end{array}$ & $\begin{array}{l}3.265 * * * \\
(0.823)\end{array}$ \\
\hline Export share & $\begin{array}{l}-2.195 * * * \\
(0.667)\end{array}$ & $\begin{array}{l}-2.178 \\
(1.518)\end{array}$ & $\begin{array}{l}-2.047 * * * \\
(0.698)\end{array}$ & $\begin{array}{l}0.247 \\
(1.211)\end{array}$ \\
\hline $\begin{array}{l}\text { Period dummies } \\
\text { Parameters of the variance of the symmetric error }\end{array}$ & Yes & Yes & Yes & Yes \\
\hline Constant & $\begin{array}{l}-2.077 * * * \\
(0.227)\end{array}$ & $\begin{array}{l}-2.196^{* * * *} \\
(0.624)\end{array}$ & $\begin{array}{l}-1.711^{* * *} \\
(0.174)\end{array}$ & $\begin{array}{l}-2.199 * * * \\
(0.428)\end{array}$ \\
\hline Number of observations & 312 & 216 & 312 & 216 \\
\hline
\end{tabular}

Standard errors in parentheses. Significance level: *** $1 \%, * * 5 \%, * 10 \%$.

$R D=$ dummy for high $\mathrm{R} \& \mathrm{D}$ intensity; $A D V=$ dummy for high advertising intensity; $I M P=$ dummy for high import competition.

\section{Table 3: Stochastic frontiers}




\begin{tabular}{|c|c|c|c|c|}
\hline \multirow[t]{2}{*}{ Limiting level of concentration } & \multicolumn{2}{|c|}{$C 3$} & \multicolumn{2}{|c|}{$H$} \\
\hline & Model 1 & Model 2 & Model 1 & Model 2 \\
\hline 1NI: Low sunk costs, low import competition & $\begin{array}{l}0.075 * * * \\
(0.009)\end{array}$ & $\begin{array}{l}0.071 * * * \\
(0.019)\end{array}$ & $\begin{array}{l}0.011 * * * \\
(0.001)\end{array}$ & $\begin{array}{l}0.011 * * * \\
(0.003)\end{array}$ \\
\hline 1I: Low sunk costs, high import competition & $\begin{array}{l}0.196 * * * \\
(0.022)\end{array}$ & $\begin{array}{l}0.098 * * * \\
(0.051)\end{array}$ & $\begin{array}{l}0.025^{* * *} * \\
(0.004)\end{array}$ & $\begin{array}{l}0.022 * \\
(0.012)\end{array}$ \\
\hline 2A: High advertising & $\begin{array}{l}0.117 * * * \\
(0.014)\end{array}$ & $\begin{array}{l}0.142 * * * \\
(0.029)\end{array}$ & $\begin{array}{l}0.022^{* * *} \\
(0.003)\end{array}$ & $\begin{array}{l}0.025 * * * \\
(0.006)\end{array}$ \\
\hline 2R: High R\&D & $\begin{array}{l}0.226 * * * \\
(0.029)\end{array}$ & $\begin{array}{l}0.176 * * * \\
(0.042)\end{array}$ & $\begin{array}{l}0.045^{* * *} \\
(0.004)\end{array}$ & $\begin{array}{l}0.036 * * * \\
(0.008)\end{array}$ \\
\hline
\end{tabular}

Standard errors in parentheses. Significance level: *** 1\%, ** 5\%, * 10\%.

Table 4: Limiting levels of concentration

\begin{tabular}{|c|c|c|c|c|}
\hline & \multicolumn{2}{|c|}{$\ln (C 3 /(1-C 3))$, Model 1} & \multicolumn{2}{|c|}{$\ln (C 3 /(1-C 3))$, Model 2} \\
\hline & $E(u)$ & $\operatorname{Var}(u)$ & $E(u)$ & $\operatorname{Var}(u)$ \\
\hline $\begin{array}{l}\text { Average marginal effect of } \\
\text { Cost disadvantage } \\
\text { Share of multiplant firms } \\
\text { Export share }\end{array}$ & $\begin{array}{l}-0.838 \\
5.053 \\
-0.541\end{array}$ & $\begin{array}{l}5.783 \\
22.619 \\
-8.225\end{array}$ & $\begin{array}{l}-1.042 \\
6.378 \\
-0.440\end{array}$ & $\begin{array}{l}2.632 \\
18.784 \\
-5.523\end{array}$ \\
\hline Export share & $\begin{array}{l}\ln ^{\ln (H} \\
E(u)\end{array}$ & $\begin{array}{l}\text {, Model } 1 \\
\operatorname{Var}(u)\end{array}$ & $\begin{array}{l}\ln ^{\ln (H} \\
E(u)\end{array}$ & $\begin{array}{l}\text {, Model } 2 \\
\operatorname{Var}(u)\end{array}$ \\
\hline $\begin{array}{l}\text { Average marginal effect of } \\
\text { Cost disadvantage } \\
\text { Share of multiplant firms } \\
\text { Export share }\end{array}$ & $\begin{array}{l}-1.537 \\
3.031 \\
-0.195\end{array}$ & $\begin{array}{l}-0.692 \\
7.071 \\
-2.114\end{array}$ & $\begin{array}{l}-1.208 \\
3.829 \\
-0.086\end{array}$ & $\begin{array}{l}-0.041 \\
7.443 \\
0.094\end{array}$ \\
\hline
\end{tabular}

Table 5: Average marginal effects of explanatory variables 


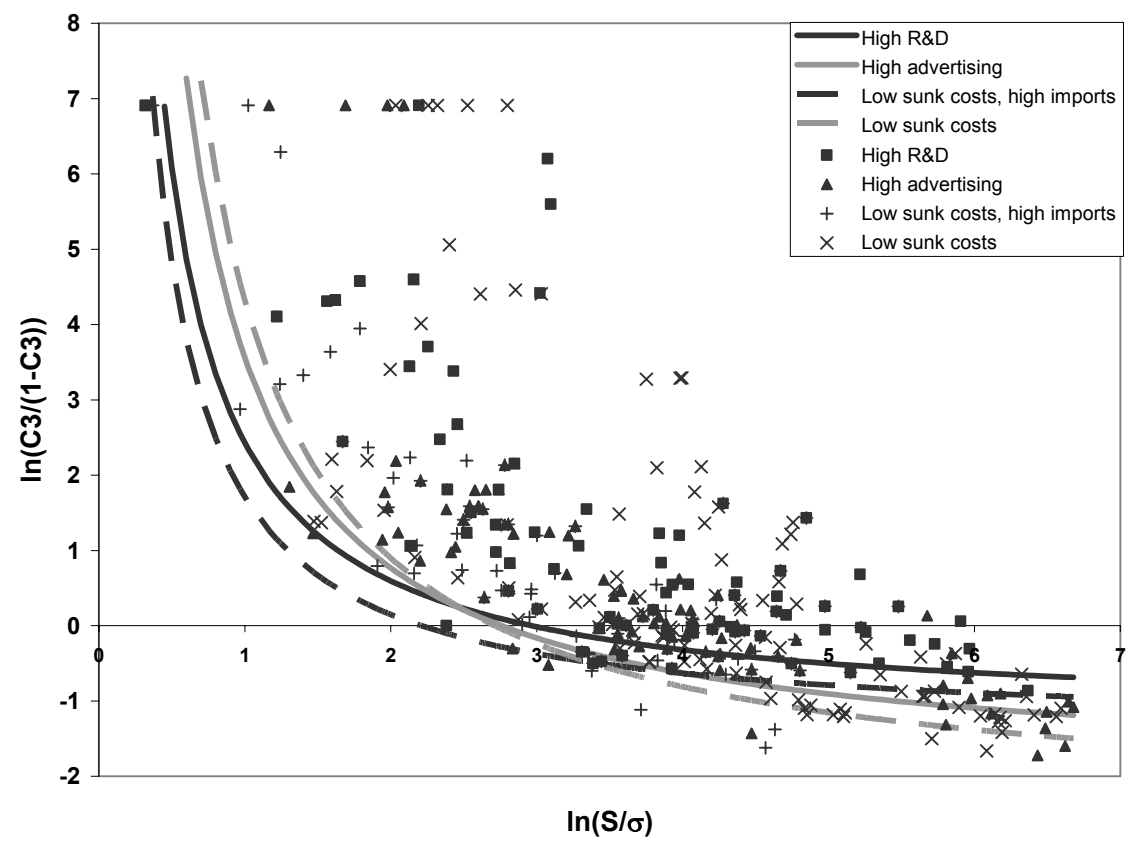

Figure 1: Lower bounds (deterministic parts of stochastic frontiers) 